\title{
The Whitehead operation procedure: Is it a useful technique?
}

\author{
Kenan Erzurumlu, Kağan Karabulut, Gökhan Selçuk Özbalcı, İsmail Alper Tarım, Gökhan Lap, Bülent Güngör
}

\begin{tabular}{|c|c|}
\hline \multirow[t]{5}{*}{ ABSTRACT } & $\begin{array}{l}\text { Objective: Hemorrhoidal disease is a very common entity in the general population; however, the therapeutic } \\
\text { approaches to hemorrhoids remain controversial. The choice of treatment method depends on the grade of the } \\
\text { hemorrhoid as well as the experience of the surgeon. The Whitehead hemorrhoidectomy procedure is often applied } \\
\text { for grade IV hemorrhoids. }\end{array}$ \\
\hline & $\begin{array}{l}\text { Material and Methods: We studied } 49 \text { patients who underwent surgery between December } 1982 \text { and January } 2013 . \\
\text { The indications for the Whitehead procedure in all patients were grade IV hemorrhoidal disease. The data on these } \\
\text { patients were evaluated retrospectively with respect to age, gender, preoperative diagnosis, and postoperative com- } \\
\text { plications. }\end{array}$ \\
\hline & $\begin{array}{l}\text { Results: Of the patients included in this study, } 34 \text { were male and } 15 \text { were female. The mean age of the patients } \\
\text { was } 41.93 \pm 12.42 \text {, and the age range was } 24-70 \text { years. Complications of the Whitehead procedure included bleeding } \\
\text { ( } 6.12 \% \text {, three cases), stricture ( } 2.04 \% \text {, one case), urinary retention ( } 16.33 \% \text {, eight cases), and temporary anal inconti- } \\
\text { nence ( } 2.04 \% \text {, one case). No patients developed Whitehead deformities, entropion, or infectious complications. All } \\
\text { patients were discharged from hospital between the fifth and eighth days post-surgery ( } 6.45 \pm 1.00 \text { days). The follow- } \\
\text { up period was } 1-234 \text { months }(70.02 \pm 54.89) \text {. }\end{array}$ \\
\hline & $\begin{array}{l}\text { Conclusion: The Whitehead procedure is successful in patients with prevalent peripheral prolapse and/or throm- } \\
\text { bosed hemorrhoids. With the right indications, and if the surgeon has adequate experience, the morbidity rate of } \\
\text { the Whitehead procedure is similar to that of other treatment methods. }\end{array}$ \\
\hline & Keywords: Whitehead, hemorrhoidectomy, hemorrhoidal disease, complication \\
\hline
\end{tabular}

Cite this paper as: Erzurumlu K, Karabulut $K$, Özbalı GS, Tarım IA, Lap G, Güngör B. The Whitehead operation procedure: is it a useful technique? Turk J Surg 2017; 33: 190-194.

This study was presented at the XIII. International Euroasian Congress of Surgery and Gastroenterology, 12-15 September 2013, Baku, Azerbaijan.

Department of General Surgery, Ondokuz Mayis University School of Medicine, Samsun, Turkey

Address for Correspondence Kenan Erzurumlu e-mail:kerzurum@omu.edu.tr

Received: 11.12.2015 Accepted: 23.04 .2016

\section{(c) Copyright 2017} by Turkish Surgical Association
Available online at www.turkjsurg.com

\section{INTRODUCTION}

Hemorrhoidal disease has been a well-known entity in general surgery for many centuries, with bleeding, anal pain, and distress being the most common symptoms. The therapeutic approaches to hemorrhoids remain controversial; the choice of treatment method depends on the grade of the hemorrhoid as well as the experience of the surgeon.

Hemorrhoidectomies are the oldest and most common surgical techniques used for the treatment of hemorrhoids. In this report, 49 cases of patients with grade IV hemorrhoidal disease who were treated using the Whitehead procedure are presented.

\section{MATERIAL AND METHODS}

Forty-nine patients who underwent the Whitehead procedure between December 1982 and January 2013 were evaluated retrospectively. Age, gender, preoperative diagnosis, postoperative complications, and length of hospital stay were evaluated. The indication for surgical treatment was grade IV hemorrhoidal disease in all the patients. Table 1 shows our algorithm for the treatment of hemorrhoidal disease.

Informed consent was not received due to the retrospective nature of the study. This research was conducted according to the principles of the World Medical Association Declaration of Helsinki “Ethical Principles for Medical Research Involving Human Subjects".

\section{Preoperative Preparation}

All patients received mechanical colonic preparation. This began $24 \mathrm{~h}$ before the surgery. Additionally, a fiber diet was applied during this period. In patients who were admitted with acute hemorrhoidal attacks (thrombosed, irreducible, or inflamed hemorrhoids), medical treatment methods, including corticosteroids, laxative agents, and warm antiseptic sitting baths, were applied prior to surgery. Surgical treatment was also delayed until the acute symptoms and signs resolved. 


\section{Surgical Procedure}

Under general or spinal anesthesia, anal dilatation was performed using two fingers with the patient in the gynecological position. An incision was then made in the skin-mucosal line extending from the 12 o'clock point to the 6 o'clock point. The anal mucosa was dissected, together with the hemor-

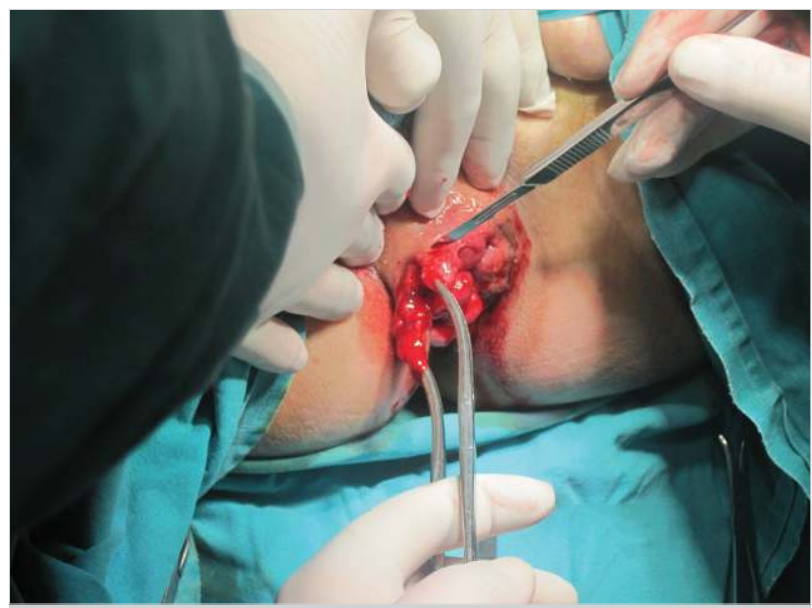

Figure 1. The anal mucosa was dissected together with the hemorrhoidal packages until the dentate line

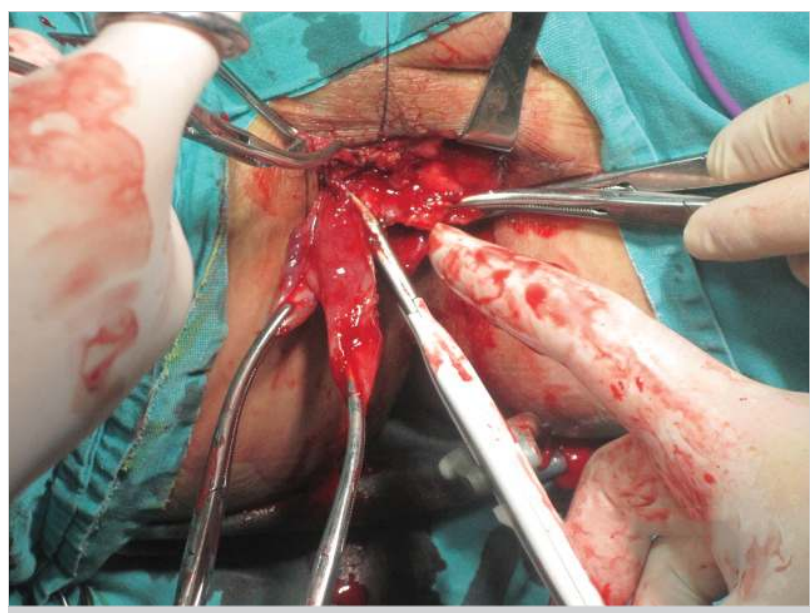

Figure 2 . The same procedure was applied symmetrically to the reciprocal remaining part of the anal mucosa rhoidal packages, up to the dentate line (Figure 1). Following this, another incision was made from the skin to the superior part of the dentate line, and the skin was sutured to the rectal mucosa. Later, the left half of the anal mucosa was excised from just above the dentate line, and the mucosa was sutured to the skin. The same procedure was applied symmetrically to the remaining reciprocal part of the anal mucosa (Figure 2). After hemostasis, a rectal tube surrounded by Spongostan was inserted through the anal canal (Figure 3).

\section{Postoperative Follow-Up}

All patients received parenteral spasmolytic and analgesic therapy for three postoperative days; if necessary, oral therapy was continued after this time. The rectal tube was maintained in place for three days in 48 patients. Intestinal peristalsis returned to normal during this period; however, in one patient, the rectal tube was removed on the first day because of intolerance.

All patients were maintained on a liquid diet for the first and second postoperative days. A normal diet was resumed on the third postoperative day.

After removal of the rectal tube, the patients received a warm antiseptic sitting bath following defecation. The anastomotic suture line was evaluated by rectal digital examination on the tenth and the thirteenth postoperative days.

\section{RESULTS}

Of the 49 patients who were included in this study, 34 were male and 15 were female. The mean age of the patients was $41.93 \pm 12.42$, and the age range was $24-70$ years.

The indications for surgical treatment were grade IV hemorrhoidal disease in all patients, anal fissures in three of the patients, and an iatrogenic sigmoid colon laceration related to rectoscopy (at another clinic) in one patient. In the last patient, the colon was repaired concurrently with the Whitehead procedure.

Twenty-three patients (46.94\%) with extensive acute thromboses and inflammation received medical treatment, including diet, laxatives, and local analgesics, as well as cortisone

Table 1. Classification, grading, and treatment of hemorrhoidal disease

\begin{tabular}{|c|c|c|c|}
\hline Classification & Grade & Findings & Treatment \\
\hline \multirow[t]{6}{*}{ Internal } & la & Hemorrhoids protrude into but do not prolapse out of the anal canal & $\mathrm{M}, \mathrm{AD}, \mathrm{RBL}, \mathrm{IP}, \mathrm{SCL}, \mathrm{CRY}, \mathrm{EC}$ \\
\hline & $\mathrm{lb}$ & Thrombosis of Grade la hemorrhoids & $\mathrm{M}$ and/or $\mathrm{H}$ \\
\hline & II & $\begin{array}{l}\text { Hemorrhoids prolapse out of the anal canal with bowel movements } \\
\text { or straining, but spontaneously reduce }\end{array}$ & M, PHSP, RBL, IP, SCL, CRY, EC \\
\hline & III & $\begin{array}{l}\text { Hemorrhoids prolapse during the previously described maneuvers } \\
\text { and must be manually reduced by the patient }\end{array}$ & $\mathrm{M}, \mathrm{RBL}, \mathrm{IP}, \mathrm{SCL}, \mathrm{CRY}, \mathrm{EC}, \mathrm{H}, \mathrm{PPH}$ \\
\hline & IVa & Hemorrhoids are prolapsed out of the anus and cannot be reduced & $\begin{array}{l}\text { Whitehead procedure, two-step } \\
\text { hemorrhoidectomy }\end{array}$ \\
\hline & $\mathrm{IVb}$ & Extensive acute thrombosis and inflammation of Grade IVa hemorrhoids & M \\
\hline External & & Even if complicated & $M, A D$, excisional $H$ \\
\hline
\end{tabular}

M: medical treatment including diet, stool-bulking agents, analgesia, and local applications; AD: anal dilatation; RBL: rubber band ligation; IP: infrared photocoagulation; SCL: sclerotherapy; CRY: cryotherapy; EC: electrocautery; H: hemorrhoidectomy (open, closed, stapled); PHSP: procedures for high sphincteric pressure; $\mathrm{PPH}$ : procedure for prolapsing hemorrhoids 


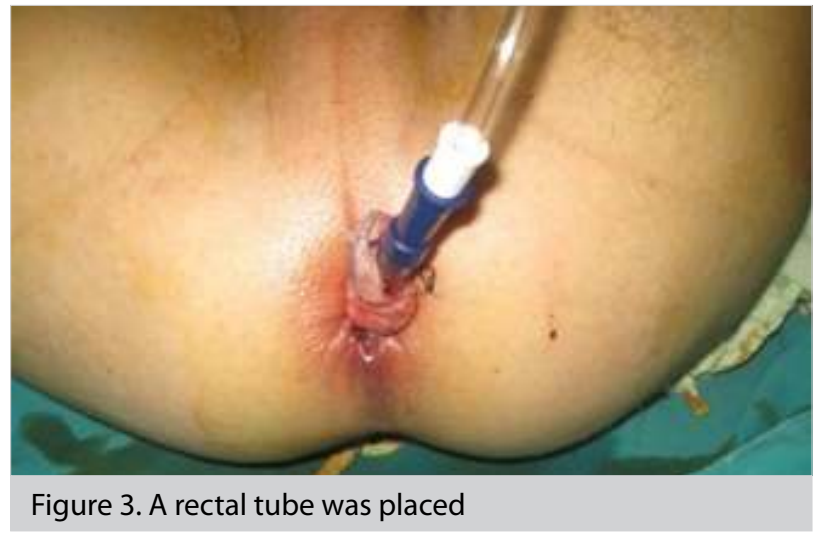

Table 2. Patient complications

\begin{tabular}{|lcc|}
\hline Complication & $\mathbf{n}$ & $\%$ \\
\hline Bleeding requiring no intervention & 3 & 6.12 \\
\hline Stricture & 1 & 2.04 \\
\hline Urinary retention & 8 & 16.33 \\
\hline Temporary anal incontinence & 1 & 2.04 \\
\hline Total & 13 & 26.53 \\
\hline
\end{tabular}

applications for three to seven days. These patients underwent operations after the acute stage. Three patients (6.12\%) developed bleeding that did not require invasive therapy or transfusions during the early postoperative period (first $24 \mathrm{~h}$ ). In the second month postoperatively, a stricture developed in one patient $(2.04 \%)$ in whom the rectal tube was removed early due to intolerance and on whom postoperative follow-up could not be performed. This patient was treated by repeated anal dilation.

Eight patients (16.33\%) had urinary retention, and a urinary catheter was inserted for 24-48 h. One patient had anal incontinence for two days following the removal of the rectal tube, which recovered spontaneously. The total morbidity rate was 26.53\% (Table 2).

No patients developed Whitehead deformities, entropion, or infectious complications (Table 2), and all patients were discharged from the hospital between the fifth and eighth days (6.45 \pm 1.00 days). The follow-up period ranged from 1 to 234 months (70.02 \pm 54.89$)$.

\section{DISCUSSION}

Hemorrhoids are mainly divided into two types: external and internal. They are also described on the basis of size and clinical findings; additionally, internal hemorrhoids are subdivided into four grades $(1,2)$.

This grading of internal hemorrhoids can be confused by complicated cases. For example, the approach to a grade I thrombosed hemorrhoid is different from the approach to a non-thrombosed hemorrhoid. Most cases of grade IV hemorrhoids involve extensive acute thromboses and inflammation; these cases can be transformed to grade III by medical treatment. Thus, we added two subgroups, grades Ib and IVb. to as grades la and IVa. Cases with thromboses and extensive acute thromboses and inflammation were described as grades $\mathrm{Ib}$ and IVb, respectively (Table 1 ).

Diet and stool-bulking agents, rubber band ligation, infrared photocoagulation, sclerotherapy, cryotherapy, and electrocautery can be used for cases of grade I to III hemorrhoids. Surgical methods such as open or closed hemorrhoidectomy, stapled hemorrhoidectomy, and the procedure for prolapsing hemorrhoids $(\mathrm{PPH})$ are procedures used for the treatment of grade III and IV cases.

Since 1882, the Whitehead procedure has been widely applied for grade IV hemorrhoids; although stapled hemorrhoidectomy and PPH have commonly been used in recent decades, they have not been found to be as successful due to high morbidity and recurrence rates (2-4). Although the Whitehead hemorrhoidectomy is controversial, it is used for grade IV hemorrhoids; furthermore, despite the common occurrence of prolapsed and/or thrombosed hemorrhoids and partial resection, it has absolute indications $(5,6)$.

The circumferential excision of the anal mucosa and hemorrhoids was first reported by Walter Whitehead (7) in 1882; however, this procedure is less preferred due to technical difficulties and a high morbidity rate. Malpractice suits also have a strong effect on these results.

During the last quarter of the $20^{\text {th }}$ century, the Whitehead procedure attracted attention. White et al. (8), Barrios et al. (9), Sagar and Wolff (10), Burchell (11), Bonello (12), and others (13-22) have reported large and successful studies with modifications of Whitehead's technique.

Complications from the Whitehead procedure are stenosis (up to $8.8 \%$ ), ectropion or wet anus (Whitehead's deformity), anal incontinence (2\%-12\%), severe pain (up to $50 \%$ ), urinary retention (2\%-50\%), fecal impaction (0.3\%), intraoperative blood loss or postoperative bleeding (0.03\%-6\%), fistula or abscess (1.1\%), complications of wound healing (1\%-2\%), and infection $(0.5 \%-5.5 \%)(5,13,14,20-22)$.

Stricture arises from fibrotic tissue proliferating and obstructing the fecal passage during the wound healing process. Although it was more frequent in the past, its incidence has been reported as less than $10 \%$ in recent publications. Stricture is prevented by regular defecation; however, the frequency of the disease increases in patients avoiding defecation due to high sphincter pressure and excessive pain. Sphincter spasm is a factor that can increase ischemia at the anastomosis; older patients have a higher risk for developing stenosis after Whitehead surgery due to sphincter spasm (15). Anal dilation is usually adequate for prevention and treatment; additionally, posterior or lateral sphincterotomy can be beneficial (16-19).

In the early stages of stricture formation, anal dilation is usually a sufficient treatment; however, in delayed cases, anoplasty may be beneficial (23). In our study, a rectal tube was maintained in the anal canal for three days for the prevention of stenosis; except for a slight increase in pain, no side effects were observed. Conversely, one patient who did not tolerate the rectal tube developed stenosis following its removal. 
The Whitehead deformity occurs as a result of rotation of the mucosa into the anal canal or outward skin due to malformation of the mucosal line. It may result from a technical error or dehiscence of the suture line. Another cause may be interventions made during a period of extensive acute thrombosis and inflammation. Technical errors may occur due to the undetermined skin-mucosal line during that period. There are two basic ways to prevent Whitehead deformity: performing a skin-to-mucosal line incision at the borderline and delaying surgery by applying medical treatment in cases of acute thrombosis and inflammation. All Grade IVb patients received medical treatment and did not undergo surgery during the acute phase.

In cases of entropion, medical treatment (moisturizingcortisone ointments) are useful. In cases of ectropion (wet anus), surgery is required. None of our patients developed the Whitehead deformity, entropion, or infectious complications.

Anal incontinence is caused by a decrease or loss of pressure in the anal sphincter. In most people with hemorrhoidal disease, the anal canal resting pressure is high. The internal sphincter accounts for $80 \%$ of the resting pressure in these cases. To decrease this pressure, a partial internal sphincterotomy or anal dilation is performed $(24,25)$. In our study, we observed that dilation performed under analgesia in grade I and grade II patients had a $95 \%$ success rate. In the patients who underwent the Whitehead procedure, anal dilation was performed routinely. We encountered short-term anal incontinence in only one patient.

Pain is associated with the incision in the anoderm and intervention in the sphincter (sphincterotomy or dilation). Spasmolytic analgesics, or even narcotic analgesics, may be necessary for treatment. These high levels of pain and weakness during bladder contractions are caused by disorders and innervation of the perianal region and may lead to urinary retention. We encountered urinary retention in eight patients; they were treated with urinary catheters for 24-48 $\mathrm{h}$.

Fecal impaction can be seen in patients with inadequate preoperative bowel preparation. Another causative factor is avoidance of defecation by patients due to pain. Complete preoperative bowel preparation and administration of laxatives that increase bowel peristalsis are sufficient for prevention.

Intraoperative blood loss or postoperative bleeding can be caused by a lack of technical ability or by errors. In rare cases, rigorous application may require additional intervention. In this study, three patients (6.12\%) developed bleeding that did not require invasive therapy or transfusions in the early postoperative period (first $24 \mathrm{~h}$ ).

Fistula/abscess formation, infection, and wound disintegration result from inadequate preparations, chemoprevention, or techniques that are not method-specific.

The limitations of this study are the low number of patients and the lack of comparison with groups of patients who underwent other surgical procedures.

\section{CONCLUSION}

The Whitehead procedure provides successful results in patients with prevalent peripheral prolapse and/or thrombosed hemorrhoids. If the surgeon is experienced and the indications are correct, the morbidity rate is similar to that of other methods.

Ethics Committee Approval: Authors declared that the research was conducted according to the principles of the World Medical Association Declaration of Helsinki "Ethical Principles for Medical Research Involving Human Subjects" (amended in October 2013).

Informed Consent: Informed consent was not received due to the retrospective nature of the study.

Peer-review: Externally peer-reviewed.

Author Contributions: Concept - K.E.; Design - K.E., K.K.; Supervision - K.E., K.K.; Resource - K.K.; Materials - G.L.; Data Collection and/or Processing - I.A.T., .G.L.; Analysis and/or Interpretation - K.K., G.S.O.; Literature Search - K.E., K.K.; Writing Manuscript - K.E., K.K.; Critical Reviews - K.K., K.E., B.G.;

Conflict of Interest: No conflict of interest was declared by the authors.

Financial Disclosure: The authors declared that this study has received no financial support.

\section{REFERENCES}

1. Corman ML. Hemorrhoids In: Corman ML Colon and rectal surgery, 4th ed. Lippincott, Philadelphia, 1998. 147-205.

2. Beck DE. Hemorrhoids. In "Handbook of Colorectal Surgery" Ed.by Beck DE. Marcek Dekker Inc. New York 2003. Ch 16 325-344.

3. Pescatori M, Favetta U, Dedola S,Orsini S. Trans anal stapled excision of rectal mucosal prolapse. Tech Coloproct 1997; 1:96-98.

4. Arezzo A, Podzemny V, Pescatori M. Surgical management of hemorrhoids. State of the art. Ann Ital Chir 2011; 82: 163-172.

5. Sungurtekin U. Radikal hemorroidektomi (Whitehead Ameliyatı). Hemoroid Hastalıkları ve Tedavisi Ed. Adil Baykan, Mehmet Füsün, Abdullah Zorluoğlu, Türk Kolon ve Rektum Cerrahisi Derneği Yayınları. İstanbul, 2007; 111-115.

6. Maria G, Alfonsi G, Nigro C, Brisinda G. Whitehead's hemorrhoidectomy. A useful surgical procedure in selected cases Tech Coloproctol 2001; 5: 93-96. [CrossRef]

7. Whitehead W. The Surgical Treatment of Haemorrhoids. Br Med J 1882; 1: 148-150. [CrossRef]

8. White JE, Syphax B, Funderburk WW A modification of the Whitehead hemorrhoidectomy. Surg Gyn Obstet 1972; 34: 103-105.

9. Barrios G, Khubchandani M. Whitehead operation revisited. Dis Colon Rectum. 1979; 22: 330-332. [CrossRef]

10. Sagar PM, Wolff BG. The use of the modified Whitehead procedure as an alternative to the closed Ferguson hemorrhoidectomy. Tech Coloproctol 2000; 3: 131-134. [CrossRef]

11. Burchell MC, Thow B, Manson RR. A "modified Whitehead" hemorrhoidectomy. Dis Colon Rectum 1976; 19: 225-232. [CrossRef]

12. Bonello JC. Who's afraid of the dentate line? The Whitehead hemorrhoidectomy. Am J Surg 1988; 156: 182-186. [CrossRef]

13. Mukhashavria GA, Qarabaki MA. Circumferential excisional hemorrhoidectomy for extensive acute thrombosis: a 14-year experience. Dis Colon Rectum 2011; 54: 1162-1169. [CrossRef]

14. Wolff BG, Culp CE. The Whitehead hemorrhoidectomy. An unjustly maligned procedure. Dis Colon Rectum 1988: 31; 587-590. [CrossRef]

15. Seow-Choen F, Low HC. Prospective randomized study of radical versus four piles haemorrhoidectomy for symptomatic large 
Erzurumlu et al.

Whitehead procedure

circumferential prolapsed piles. Br J Surg 1995; 82: 188-189. [CrossRef]

16. Boccasanta P, Venturi M, Orio A, Salamina G, Reitano M, Cioffi U, et al. Circular hemorrhoidectomy in advanced hemorrhoidal disease. Hepato-Gastroenterology 1998; 45: 969-972.

17. Devien CV, Pujol JP. Total circular hemorrhoidectomy. Int Surg 1989; 74: 154-157.

18. Denis J, Dubois N, Ganansia R, du Puy-Montbrun T, Lemarchand N. Hemorrhoidectomy: Hospital Leopold Bellan procedure. Int Surg 1989; 74: 152-153.

19. Rand AA. Whitehead's radical circumferential hemorrhoidectomy. Modified by sliding skin-flap grafts. Surg Clin North Am 1972; 52: 1031-1045. [CrossRef]

20. Andrews E. Disastrous results following Whitehead's operation and the so-called American operation. Columbus Med J 1895; 15: 97-106.
21. Geçim IE. Hemoroidal Hastalık. In "Anorektal Bölgenin Selim Hastalıkları" Ed. Menteş B, Bulut MT, Alabaz Ö, Leventoğlu S. Türk Kolon ve Rektum Cerrahisi Derneği Yayınları. İstanbul, 2011; 53-69.

22. Bullard KM, Rothenberger DA. Colon, Rectum and Anus. In "Schwartz's Principles of Surgery" Ed by Brunicardi FC, et al. Eight edition Mc Graw Hill Com. New York 2005. Ch 28, 1055-1117.

23. Maria G, Brisinda G, Civello IM. Anoplasty for the treatment of anal stenosis. Am J Surg 1998; 175: 158-160. [CrossRef]

24. Alexander-Williams J, Crapp AR. Conservative Management of Hemorrhoids: Partial Internal Sphincterotomy. Clin Gastroenteral 1975; 4: 595-618.

25. Schouten WR. van Vroonhoven TJ Lateral Internal Sphincterotomy in the Treatment of Haemorrhoids. A clinical and manometric study. Dis Colon Rectum 1986; 29: 869-872. [CrossRef] 